\title{
Проблемы репродукщии
}

\section{КОЛИЧЕСТВЕННЫЕ И КАЧЕСТВЕННЫЕ ПОКАЗАТЕЛИ СПЕРМОПРОДУКЦИИ У ГОЛШТИНСКИХ БЫКОВ В ЗАВИСИМОСТИ ОТ ГЕОМАГНИТНОЙ АКТИВНОСТИ*}

\author{
Б.С. ИОЛЧИЕВ1, П.М. КЛЕНОВИЦКИЙ 1 , А.В. ТАДЖИЕВА², Р.Б. ИОЛЧИЕВ 3
}

Магнитные бури - одни из важнейших абиотических факторов, воздействующих на биообъекты. Влияние магнитных бурь носит сложный характер и может проявляться в организме на разных уровнях. В период геомагнитной активности увеличивается частота обострений хронических заболеваний, нарушаются функции ряда систем. Сперматозоиды подвергаются действию различных биотических и абиотических факторов как в организме, так и вне его. Однако сообщения о влиянии геомагнитной активности на репродуктивную функцию, в частности на количество и качество спермы, объективно весьма ограничены, а для сельскохозяйственных видов животных подобных сведений в доступной литературе мы не обнаружили. Цель нашей работы заключалась в исследовании взаимосвязи геомагнитной активности с количественными и качественными показателями спермопродукции у быков-производителей голштино-фризской породы $(n=10$, АО «Головной центр по воспроизводству сельскохозяйственных животных», Московская обл., 2018 год). Мониторинг К-индекса геомагнитной обстановки проводили по данным Институтаземного магнетизма, ионосферы и распространения радиоволн им. Н.В. Пушкова РАН (г. Москва). Статистический анализ выполняли с помощью программы SPSS v.15.0 с использованием однофакторного дисперсионного анализа (ANOVA) (фактор, влияющего на биологическую полноценность спермы быков-производителей, - К-индекс). Сравнение показателей между группами проводили методом Scheffe-test. Качество сперматозоидов в эякулятах оценивали с использованием световой микроскипии (Nikon Eclipse Ni, «Nikon», Япония) и программного обеспечения Argus-CASA («ArgusSoft», Россия). Полученные в настоящей работе результаты показывают, что магнитная буря достоверно влияет на спермопродукцию у быков-производителей. Статистически значимые различия были установлены по объему эякулята $(\mathrm{F}=6,49 ; \mathrm{p}<0,05)$ и содержанию непрогрессивно-подвижных сперматозоидов в эякуляте $(\mathrm{F}=8,36 ; \mathrm{p}<0,05)$. В период магнитной бури (К-индекс $\geq 5,0)$ объем эякулята, полученного от быков-производителей, снижался на $28,2 \%(p<0,001)$ по сравнению с периодом отсутствия геомагнитных возмущений (K-индекс $\leq 1,0)$. Геомагнитные возмущения привели к снижению активности сперматозоидов на $11.3 \%(\mathrm{p}<\mathbf{0 , 0 0 1})$.

Ключевые слова: магнитная буря, быки-производители, сперматозоиды, подвижность сперматозоидов, морфология сперматозоидов, хроматин, яДНК, индекс фрагментация ДНК, CASA.

Магнитные бури - один из природных абиотических факторов, влияющих на живые организмы $(1,2)$. Детали зависимости биологических процессов от состояния геомагнитного поля еще не до конца изучены, но признается, что большинство физиологических ритмов синхронизируются с солнечной и геомагнитной активностью (3-6). При этом как у отдельных клеток, так и у организма в целом реакция на внешние воздействия зависит не только от их характера и силы, но и от свойств самих биообъектов (7).

В период магнитных бурь обостряются хронические заболевания сердечно-сосудистой, центральной нервной систем, нарушается кровоток (8-10), заметно усиливается секреция адреналина надпочечниками, изменяется состояние вегетативной нервной системы, которая регулирует работу внутренних органов и желез внутренней секреции (11). С изменением геомагнитной активности связана продукция мелатонина $(12,13)$, который участвует в регуляции циркадных ритмов, улучшает работу эндокринной (14), иммунной (15), репродуктивной $(16,17)$ систем.

Влияние геомагнитной активности на клеточном уровне объясняют изменением состояния и функций клеточных мембран, нарушением трансмембранного транспорта, образованием продуктов свободнорадикального

* Работа выполнена при поддержке гранта РФФИ №18-016-00128 А.

1196 
окисления липидов, уменьшением буферной емкости антиоксидантной системы (18). В то же время данные об эффектах магнитных полей на клетки противоречивы. Так, статическое магнитное поле не вызывало оксидативного стресса в фибробластах мыши и даже приводило к некоторому повышению антиоксидантной активности (19). Некоторые клеточные компартменты, например митохондрии и эндоплазматический ретикулум, более чувствительны к воздействию магнитных полей (20).

Сперматозоиды подвергаются воздействию различных биотических и абиотических факторов как в организме, так и вне организма (21-23). Большинство из этих факторов оказывают косвенное и прямое воздействие на репродуктивные качества быков-производителей. Степень влияния внешних факторов на сперматозоиды зависит от характера этих факторов и от состояния самих сперматозоидов. Внешние факторы могут вызывать изменения в морфологии, ядре, акросоме, митохондриях и других структурах. Существенное влияние на подвижность и морфологию сперматозоидов оказывают электромагнитные поля $(24,25)$.

Важнейший показатель, характеризуюший биологическую полноценность сперматозоидов, - состояние ядерной ДНК в хроматине, от которого во многом зависит фертильность самцов. На степень фрагментации ядерной ДНК сперматозоидов влияют многочисленные биотические и абиотические факторы (26).

Таким образом, многочисленные, в основном медицинские, наблюдения свидетельствуют о зависимости физиологического состояния, функциональной активности и рисков обострения ряда патологий от воздействия на организм магнитных бурь, но при этом сообщения о влиянии геомагнитной активности на репродуктивную функцию, в частности на количество и качество спермы, объективно крайне ограничены. Для сельскохозяйственных видов животных подобных сведений в доступно литературе мы не обнаружили, хотя в современном животноводстве, основанном на масштабном применении криоконсервированной спермы и искусственного осеменения, проблема достаточного количества биологически полноценного семени производителей стоит очень остро. Углубленное изучение этой темы на сельскохозяйственных видах также важно для понимания влияния магнитных бурь на мужские половые клетки in vivo (на уровне организма) в дополнение к выявлению механизмов клеточных ответов на действие магнитных и электромагнитных полей in vitro.

В своей работе мы показали, что у голштинов магнитная буря статистически значимо влияет на объем эякулята $(\mathrm{F}=6,49, \mathrm{p}<0,05)$ и содержание в нем непрогрессивно-подвижных сперматозоидов $(\mathrm{F}=8,36, \mathrm{p}<0,05)$. В период магнитной бури объем эякулята снижается на 28,2 \% (p < 0,001), активность сперматозоидов - на $11,3 \%$ ( $<<0,001)$.

Цель выполненного исследования - определить, изменяются ли количественные и качественные показатели спермопродукции у крупного рогатого скота под влиянием геомагнитной активности.

Методика. Для исследования сформировали группу из 10 быковпроизводителей голштинской породы (АО «Головной центр по воспроизводству сельскохозяйственных животных», Московская обл., 2018 год) в возрасте 3-5 лет с живой массой 900-1100 кг. Условия кормления и содержания животных были одинаковыми и соответствовали разработанным нормам (ФГБНУ ФНЦ животноводства - ВИЖ им. академика Л.К. Эрнста). Сбор спермы проводили операторы АО «Головной центр по воспроизводству сельскохозяйственных животных» в соответствии с Национальной технологией замораживания и использования спермы племенных быков- 
производителей (27). От каждого быка брали два эякулята с промежутком 10-15 мин. Эякуляты в зависимости от концентрации разбавляли синтетической средой OPTIXcell ${ }^{\mathrm{TM}}$ («IMV Technologies», Франция). На свежесобранных образцах учитывали объем эякулятов и определяли качественные показатели спермы. Исследовали по 3 образца каждого исследуемого эякулята (общий объем выборки - 360 образцов).

Для определения концентрации и подвижности сперматозоидов использовали камеру Маклера (счетная камера спермы) («Sefi Medical Instruments», Израиль) и систему компьютеризованного анализа - микроскоп Nikon Eclipse Ni, оснащенный камерой Nikon DS-Qi2 с высоким разрешением $(4908 \times 3264)$ («Nikon», Япония) (программное обеспечение ArgusCASA - Computerized Assisted Semen Analysis, «ArgusSoft», Россия). Для анализа подвижности получали данные не менее чем для 300 сперматозоидов. Оценивали следующие показатели: VAP (average path velocity, Mм/c) средняя скорость движения головки по усредненной траектории, мкм/с; VSL (straight-linevelocity, мкм/c) - скорость прямолинейного движения головки, мКм/с (средняя скорость движения головки сперматозоида вдоль прямого отрезка между начальной и конечной точкой траектории); VCL (curvilinear velocity, мкм/c) - фактическая скорость движения сперматозоидов по реальной траектории, мкм/c; ALH (amplitude of lateral head displacement, мкм) - среднее отклонение головки, мкм (амплитуда латерального смещения головки сперматозоида относительно траектории движения); BCF (beat-cross frequency, Гц) - частота колебательных усредненных движений, Гц (средняя частота пересечения криволинейной траектории движения сперматозоида с его усредненной траекторией за единицу времени); STR (straightness, VSL/VAP) - степень прямолинейности направленного движения сперматозоидов (по средней траектории движения, \%; LIN (linearity, VSL/VCL, \%) - степень волнистости треков (колебания истинной траектории движения по отношению к средней траектории), \%.

При приготовлении мазков для морфологических исследований на обезжиренное предметное стекло наносили каплю спермы, с помощью пластикового шпателя распределяли ее тонким слоем и высушивали при комнатной температуре, полученные препараты окрашивали (набор КвикДифф, «Абрис+», г. Санкт-Петербург) в соответствии с прилагаемым протоколом. Препараты анализировали в автоматическом режиме с помощью программного обеспечения Argus-CASA в соответствии со строгими критериями Крюгера, результаты выражали в абсолютных значениях (количество сперматозоидов с анормальной морфологии), а так же как процентное соотношение (соотношение сперматозоидов с анормальной морфологией к общему количеству сперматозоидов, выраженное в процентах).

Фрагментацию ДНК в сперматозоидах (тест на дисперсию хроматина Sperm Chromatin Dispersion Test, SCD-test) изучали с использованием набора Halosperm ${ }^{\circledR}$ kit («Laboratories INDAS S.A.U.», Испания) согласно прилагаемой инструкции. Микроскопию проводили при увеличении $\times 40 \mathrm{c}$ использованием микроскопа Альтами ЛЮМ-2, оснащенного цифровой камерой UCMOS14000KPA (Россия).

В зависимости от размера ореола сперматозоиды разделяли на пять классов: без фрагментации ДНК - большой ореол, средний ореол; с фрагментированной ДНК - малый ореол, отсутствие ореола; вырожденные - ядро необычной формы или слабо окрашено. Классификацию по степени фрагментации проводили с помощью программного обеспечения Argus-CASA, процентное соотношение сперматозоидов с разной степенью фрагментации ДНК рассчитывалась в автоматическом режиме. 
Статистический анализ проводили с помощью программы IBM SPSS Statistics 15.0 («IBM Corp.», США). Вычисляли средние арифметические $(M)$ и стандартные ошибки средних $( \pm \mathrm{SEM})$. Для оценки значимости влияния фактора геомагнитной активности на параметры сперматозоидов выполняли однофакторный дисперсионный анализ (ANOVA), опредяляя F-критерии и р-значимость. Для выявления разницы между группами пользовались методом множественных сравнений Шеффе (Scheffe). При $\mathrm{p}<0,001$ различия считали статистически высокодостоверными, при $\mathrm{p}<0,01$ и $\mathrm{p}<0,05-$ достоверными.

Результаты. За 8 мес наблюдения (с января по октябрь 2018 года), по данным Института земного магнетизма, ионосферы и распространения радиоволн им. Н.В. Пушкова РАН (г. Москва) (http://geodata.izmiran.ru/), в районе исследования 4 раза (27 февраля, 20 апреля, 25 июня и 27 августа) были зафиксированы магнитные бури с К-индексом $\geq 5,0$ (К-индекс геомагнитной обстановки характеризует отклонение магнитного поля Земли от нормы в течение 3-часового интервала; имеет значения от 0 до 9).

В таблице 1 приведенные среднее данные спермограммы исследуемых быков-производителей в динамике в зависимости от геомагнитной активности.

1. Средние показатели спермограммы быков-производителей в зависимости от Киндекса геомагнитной активности ( $M \pm \mathrm{SEM}$, январь-октябрь 2018 года)

\begin{tabular}{|c|c|c|c|c|c|c|c|c|c|c|}
\hline $\begin{array}{l}\text { Номер } \\
\text { быка }\end{array}$ & $\begin{array}{l}\text { Объем, } \\
\text { мл }\end{array}$ & PR, \% & NP, \% & IM, \% & $\begin{array}{l}\text { VAP, } \\
\mathrm{MKM} / \mathrm{c}\end{array}$ & $\begin{array}{l}\text { VSL, } \\
\text { MKM/c }\end{array}$ & $\begin{array}{l}\text { VCL, } \\
\mathrm{MKM} / \mathrm{c}\end{array}$ & $\begin{array}{l}\text { ALH, } \\
\text { MKM }\end{array}$ & $\begin{array}{l}\mathrm{BCF}, \\
\mathrm{Hz}\end{array}$ & STR, \% LIN, \% \\
\hline & & $883+26$ & $7,2 \pm 0,9$ & $4,5 \pm 0,3$ & & & $127,5 \pm 3,7$ & $\underline{5,3 \pm 0,9}$ & $28,5 \pm 1,1$ & $80,0 \pm 3,262,5 \pm 0,9$ \\
\hline & & & & & & & & & $22,0 \pm 0$ & \\
\hline & & & & & & & & & & \\
\hline & & & & & & & & & & \\
\hline & & & & & & & & & & \\
\hline & & & & & & & & & & \\
\hline & & & & & & & & & & \\
\hline & & & & & & & & & & \\
\hline & & & & & , $0 \perp 1,0$ & & 1 & & $29,2 \pm 0$ & 0,9 \\
\hline & & & & & & & & & & \\
\hline & & & & & 1,9 & & & & $2 T, J \pm 1$, & \\
\hline & & & & & & & & & & \\
\hline & & & & & & & $-3.8 \quad-\quad$ & & $0+1$ & \\
\hline & & & & & & & & & & \\
\hline & & & & ,2 & $=1,7$ & & & & $4 \pm 1$, & 0,8 \\
\hline & & & & & & & & & & \\
\hline & & & & & $\underline{88,0 \pm 2,8}$ & & & & & \\
\hline & & & & & $77,5 \pm 1,6$ & & $\pm 1,3$ & & & 2,7 \\
\hline \multirow{2}{*}{10} & $4,8 \pm 0$, & $\underline{85,1 \pm 2,5}$ & & $\underline{7,7 \pm 0,1}$ & $\underline{85,0 \pm 1,9}$ & $\underline{67,6 \pm 2,5}$ & $\pm 2,5$ & $\pm 0,2$ & $\underline{26,1 \pm 2,1}$ & $\pm 0,9$ \\
\hline & $3,3 \pm 0$ & & & $8,0 \pm 0,2$ & $73,0 \pm 3,8$ & $62,0 \pm 3,4$ & & & & 1,7 \\
\hline \multicolumn{11}{|c|}{$\begin{array}{l}\text { П р и м е ч а н и е. PR - прогрессивно-подвижные; NP - непрогрессивно-подвижные; IM - неподвиж- } \\
\text { ные; VAP - средняя скорость движения головки по усредненной траектории, VSL - скорость прямоли- } \\
\text { нейного движения головки, VCL - фактическая скорость движения сперматозоидов по реальной траек- } \\
\text { тории, ALH - среднее отклонение головки, BCF (beat-cross frequency) - частота колебательных усред- } \\
\text { ненных движений, STR - степень прямолинейности направленного движения сперматозоидов, LIN - } \\
\text { степень волнистости треков. Над чертой - показатели при } \mathrm{K} \leq 1,0 \text {, под чертой }- \text { при } \mathrm{K} \geq 5,0 \text {. }\end{array}$} \\
\hline
\end{tabular}

Дисперсионный анализ показал, что магнитная буря достоверно влияет на объем эякулята быков-производителей $(\mathrm{F}=6,49, \mathrm{p}<0,05)$ и на долю непрогрессивно-подвижных сперматозоидов в эякуляте $(\mathrm{F}=8,36$, $\mathrm{p}<0,05)$ (табл. 2). В период магнитной бури объем полученного эякулята снижался на 28,2 \% (р $<0.001$, тест Шеффе, см. табл. 2) по сравнению с получаемым в период, когда магнитная обстановка нормальная и К-индекс $\leq 1,0$. Под влиянием магнитной бури, когда индекс геомагнитной активности составлял 5 баллов и выше, подвижность сперматозоидов снизилась на $11,3 \%$ ( $<<0,001)$. Повышенная геомагнитная активность сопровождается увеличением доли сперматозоидов с манежным и колебательным движением. В дни с возмущенной геомагнитной обстановкой все парамет- 
ры, характеризующие активность сперматозоидов, статистически значимо снижались: VAP - на 10,9 мкм/с (р <0,01), VSL - на 9,1 мкм/с $(\mathrm{p}<0,01)$, ALH - на 0,7 мкм/c (p < 0,01) (см. табл. 1).

2. Объем эякулятов и подвижность сперматозоидов в эякулятах голштинских быков-производителей в периоды с разной геомагнитной активностью $(M \pm \mathrm{SEM}$, $n=360$, АО «Головной центр по воспроизводству сельскохозяйственных животных», Московская обл., 2018 год)

\begin{tabular}{|c|c|c|}
\hline \multirow{2}{*}{ Показатель } & \multicolumn{2}{|c|}{ Индекс геомагнитной активности } \\
\hline & $\mathrm{K} \leq 1,0$ (спокойная геомагнитная обстановка) & $\mathrm{K} \geq$ 5,0 (магнитная буря) \\
\hline Объем эякулята, мл & $4,82 \pm 0,14$ & $3,76 \pm 0,15^{* * *}$ \\
\hline $\mathrm{PR}, \%$ & $85,60 \pm 1,20$ & $74,30 \pm 1,50^{* * *}$ \\
\hline $\mathrm{NP}, \%$ & $6,70 \pm 1,30$ & $17,50 \pm 1,90^{* *}$ \\
\hline $\mathrm{IM}, \%$ & $7,70 \pm 1,80$ & \\
\hline VAP, MKM/c & $85,70 \pm 1,60$ & 74,80 \\
\hline VSL, MKм/c & $71,50 \pm 2,30$ & 62,4 \\
\hline VCL, МКм/c & $118,40 \pm 3,20$ & $106,10 \pm 2,10^{* *}$ \\
\hline ALH, мкм & $4,90 \pm 0,10$ & $4,20 \pm 0,20^{* *}$ \\
\hline $\mathrm{BCF}, \mathrm{Hz}$ & $27,30 \pm 0,90$ & 21,2 \\
\hline STR, \% & $77,70 \pm 3,10$ & 72,4 \\
\hline LIN, \% & $61,50 \pm 2,50$ & $59,20 \pm 1,70^{*}$ \\
\hline \multicolumn{3}{|c|}{ 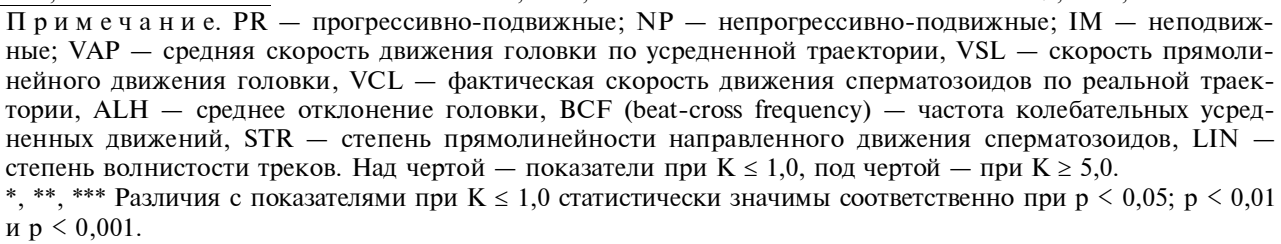 } \\
\hline
\end{tabular}

3. Результаты однофакторного дисперсионного анализа частоты (\%) патологий сперматозоидов по морфологии в эякулятах голштинских быков-производителей в периоды с разной геомагнитной активностью по группам в зависимости от К-индекса $(M \pm \mathrm{SEM}, n=360$, АО «Головной центр по воспроизводству сельскохозяйственных животных», Московская обл., 2018 год)

\begin{tabular}{llrrr|r|c|c}
\hline \multicolumn{1}{c}{ Тип патологии } & \multicolumn{1}{c|}{ Сравнение } & \multicolumn{1}{c}{ SS } & df & MS & F & p \\
Патологические фор- & Между группами & 84,535 & 2 & 42,267 & 3,509 & 0,039 \\
мы сперматозоидов & Внутри групп & 493,897 & 34 & 12,046 & & \\
& Итого & 578,432 & 36 & & & 0,699 \\
Патология головки & Между группами & 0,200 & 2 & 0,100 & 0,385 & \\
& Внутри групп & 1,300 & 34 & 0,260 & & 0,234 \\
Патология шейки & Итого & 1,500 & 36 & & & \\
& Между группами & 26,449 & 2 & 13,224 & 1,515 & 0,034 \\
& Внутри групп & 296,794 & 34 & 8,729 & & \\
Патология жгутика & Итого & 323,243 & 36 & & & \\
& Между группами & 6,451 & 2 & 3,225 & 2,324 & \\
& Внутри групп & 19,432 & 34 & 1,388 & & \\
& Итого & 25,882 & 36 & & &
\end{tabular}

П р и м е ч а н и е. SS - сумма квадратов, df - число степеней свободы, MS - средняя квадратов, F - критерий Фишера, p - статистическая значимость; I группа образцов - при $\mathrm{K} \leq 1$, II группа - при $\mathrm{K} \geq 5$.

Однофакторный дисперсионный анализ морфологических изменения сперматозоидов в зависимости от геомагнитной активности показал, что различия между группами по средним значениям для содержания всех патологических форм и патологий жгутика сперматозоидов достоверны, а уровни статистической значимости при этом составляют соответственно $\mathrm{p}=0,039$ и $\mathrm{p}=0,034$ (табл. 3). Статистическая значимость F-критерия для частоты встречаемости патологи головки $\mathrm{p}=0,699$ и шейки $\mathrm{p}=0,234$ $>0,05$, следовательно, по этим показателям нулевая гипотеза различия между группами не опровергается.

В дни с повышенной геомагнитной активностью число сперматозоидов с патологией увеличивалось. При $\mathrm{K} \geq 5,0$ (магнитные бури) их доля составила $8,14 \%$, что на 59,9 \% больше, чем при $\mathrm{K} \leq 1,0$ (спокойная геомагнитна обстановка). Выявились статистически значимые различия по 
частоте патологий жгутика (рис. 1) в зависимости от геомагнитной активности. При магнитной буре число таких спермиев возрастало на 40,7 \%, $(\mathrm{p}<0,05)$ что привело к увеличению численности клеток с манежным колебательным движением (непрогрессивно-подвижные клетки) (табл. 4).

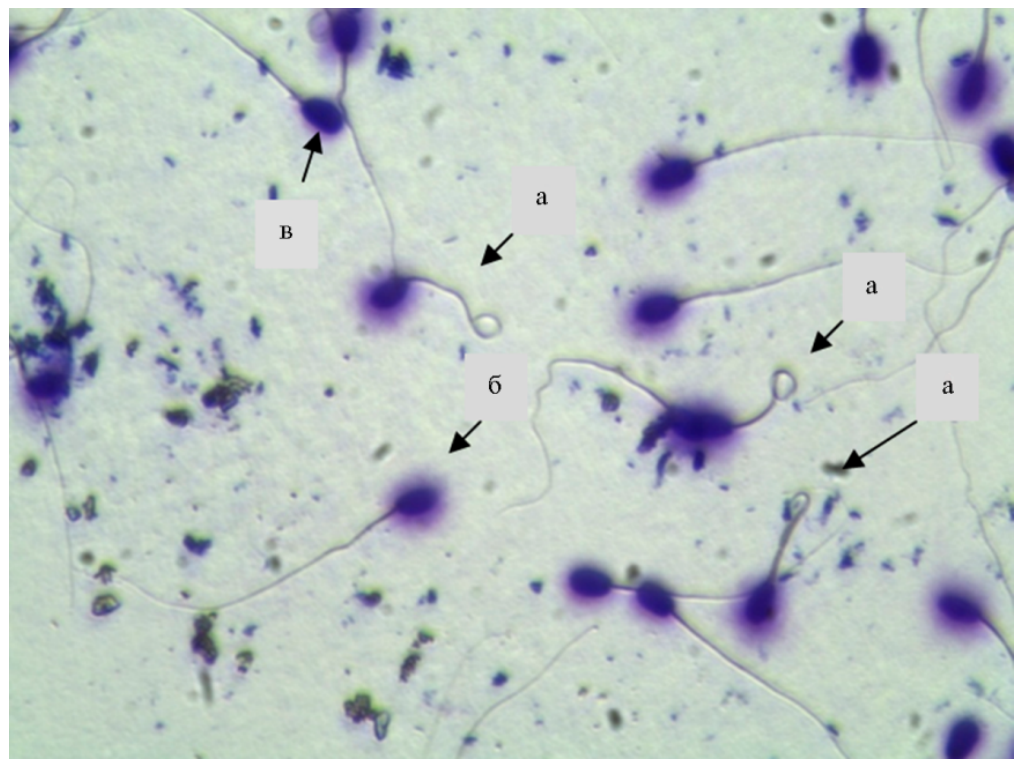

Рис. 1. Результаты теста на дисперсию хроматина (Sperm Chromatin Dispersion Test, SCD-test) в сперматозоидах голштинских быков-производителей: а - патология жгутика, б - сперматозоид без фрагментации ДНК, в - сперматозоид с фрагментированной ДНК (АО «Головной центр по воспроизводству сельскохозяйственных животных», Московская обл., 2018 год). Микроскоп Альтами ЛЮМ-2 с цифровой камерой UCMOS14000KРA (Россия), увеличение $\times 40$.

4. Доля сперматозоидов с патологией в эякулятах голштинских быков-производителей в периоды с разной геомагнитной активностью по группам в зависимости от K-индексов $(M \pm \mathrm{SEM}, n=360$, АО «Головной центр по воспроизводству сельскохозяйственных животных», Московская обл., 2018 год)

\begin{tabular}{l|c|c}
\hline \multicolumn{1}{c}{ Показатель, \% } & \multicolumn{2}{c}{ Индекс геомагнитной активности } \\
\cline { 2 - 3 } & $\mathrm{K} \leq 1,0$ & $\mathrm{~K} \geq 5,0$ \\
\hline Патологические формы сперматозоидов & $4,88 \pm 0,55$ & $8,14 \pm 0,36^{*}$ \\
Патология головки & $1,25 \pm 0,16$ & $1,28 \pm 0,19$ \\
Патология шейки & $1,64 \pm 0,30$ & $2,30 \pm 0,24$ \\
Патология жгутика & $4,51 \pm 0,49$ & $6,35 \pm 0,35^{*}$ \\
* Различия между показателями при $\mathrm{K} \leq 1,0$ статистически значимы статистически значимы при $\mathrm{p}<0,01$. \\
\hline
\end{tabular}

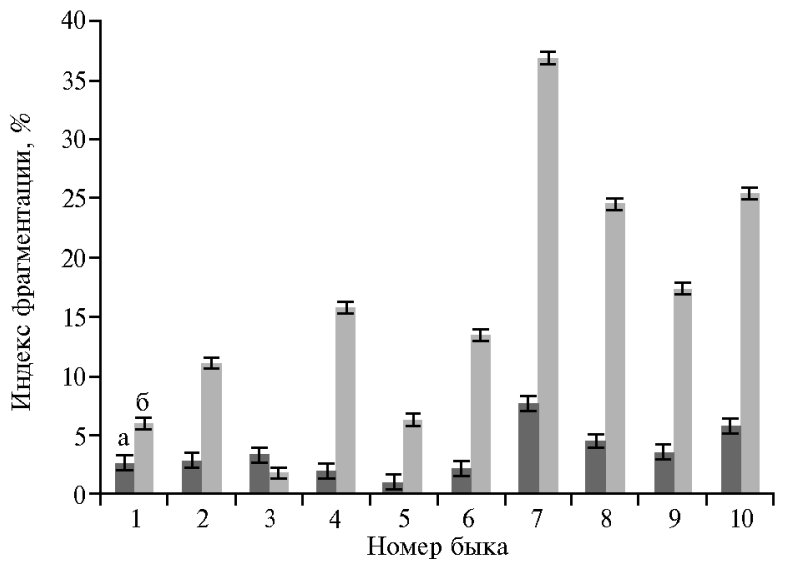

Рис. 2. Индекс фрагментации ядерной ДНК в сперматозоидах из эякулятов голштинских быков-производителей в периоды с разной геомагнитной активностью: $\mathrm{a}-$ при $\mathrm{K} \leq 1,0 ;$ б - при $\mathrm{K} \geq 5,0$ (АО «Головной центр по воспроизводству сельскохозяйственных животных», Московская обл., 2018 год).

В образцах, полученных от быков-производителей в дни, когда были зафиксированы магнитные бури, индекс фраг- 
ментации ядерной ДНК значительно превышал показатели при $\mathrm{K} \leq 1,0$ (рис. 2).

Исследования воздействия магнитных бурь на биологические объекты указывает на существование тесной зависимости физиологических ритмов от геомагнитной активности (4-6). Проведенное нами изучение связи между биологической полноценностью сперматозоидов в эякулятах и геомагнитной активностью показывает, что магнитные бури отрицательно влияют на количественные (уменьшение объема эякулята в среднем на $22 \%)(\mathrm{p}<0,001)$ и качественные показатели эякулята (доля прогрессивно подвижных сперматозоидов снизилась на $11,3 \%$ при р < 0,001, непрогрессивно-подвижных - возросла на $10,8 \%$ при р $<0,01)$. Подвижность сперматозоидов - один из основных параметров, характеризующих фертильность самцов. В зависимости от подвижности сперматозоидов, быковпроизводителей используют для воспроизводства (28). Эякуляты с показателями подвижности сперматозоидов ниже 70 \% выбраковываются. Прогрессивное движение сперматозоидов необходимо для достижения ими яйцеклеток. Отсутствие или низкое содержание в эякуляте сперматозоидов с прямолинейно-поступательным движением становится причиной бесплодия $(26,28,29)$.

Эффект, оказываемый геомагнитными возмущениями, имеет сложный характер и зависит как от их силы, так и от состояния самих биологических объектов и их систем (24). Анализ спермограммы быков-производителей в динамике показывают, что у исследуемых животных в дни геомагнитной активности снижались показатели спермопродукции. Следует отметить, что реакция быков-производителей на геомагнитную обстановку была индивидуальной: уменьшение числа прогресивно-подвижных сперматозоидов у особей колебалось от 11 до $16 \%(\mathrm{p}<0,05)$.

Многочисленные исследования подтверждают влияние абиотических факторов на сперматозоиды как при воздействии таких агентов на отцовский организм, так и в эякулятах или при нахождении в половых путях самки (21-23). Происходят изменения в общей морфологии, состоянии ядра и акросомы, в митохондриях, жгутике и других структурах сперматозоидов $(24,25)$. Мы наблюдали увеличение (на $40 \%$, p < 0,05) доли сперматозоидов с анормальной морфологией в период геомагнитной активности. При этом в наибольшей степени (на 40,1 \%, p < 0,05) возрастала доля сперматозоидов с патологией жгутика.

Целостность яДНК в хроматине спермы - важнейшая характеристика биологической полноценности сперматозоидов $(30,31)$, она также определяет фертильность, эффективность оплодотворения яйцеклеток и развитие эмбриона (32). Наше исследование подтвердило факт увеличения индекса фрагментации ДНК в сперматозоидах из эякулятов, собранных в дни геомагнитных возмущений. Степень фрагментации варьировала от 1,80 до $38,84 \%$, также свидетельствуя о том, что реакции на геомагнитную активность в определенной мере зависит от индивидуальных особенностей организма. Известно, что одним из факторов, вызывающих фрагментацию ДНК в хроматине сперматозоидов, служит окислительный стресс $(32,33)$. Плазматическая мембрана сперматозоида содержит большое количество полиненасыщенных жирных кислот, что делает эти половые клетки более чувствительными к такому стрессу.

Итак, полученные в представленном исследовании данные свидетельствуют о влиянии геомагнитной активности на качественные и коли- 
чественные характеристики спермы быков, полученной в дни магнитной бури. Сравнительный анализ показателей биологической полноценности спермы свидетельствует о росте частоты морфологический аномалий и повышении индекса фрагментации ядерной ДНК в сперматозоидах из таких эякулятов. Эти данные, полученные in vivo, важны для практики применения репродуктивных технологий. Наблюдаемые эффекты следует рассматривать как некую результирующую воздействия магнитного поля на организменном уровне. Более детальное представление о происходящих при этом процессах можно получить при углубленном изучении физиологического статуса животных и функциональной активности систем организма, прежде всего репродуктивной и нейрогуморальной. Для фундаментального изучения молекулярных механизмов, вовлеченных в эти взаимодействия и обеспечивающих клеточный ответ на действие геомагнитных полей, будут продолжены эксперименты с эякулированными сперматозоидами крупного рогато скота in vitro.

\section{ЛИТЕРАТУРА}

1. Liboff A.R. The electromagnetic field as a biological variable. In: On the nature of electromagnetic field interactions with biological systems /A.N. Frey, R.J. Langes (eds.). Austin, 1994: 59-72.

2. Binhi V.N., Prato F.S. Biological effects of the hypomagnetic field: an analytical review of experiments and theories. PLOS ONE, 2017, 12(6): e0179340 (doi: 10.1371/journal.pone.0179340).

3. McCraty R., Atkinson M., Stolc V., Alabdulgader A.A., Vainoras A., Ragulskis M. Synchronization of human autonomic nervous system rhythms with geomagnetic activity in human subjects. Int. J. Environ. Res. Public Health, 2017, 14(7): 770 (doi: 10.3390/ijerph14070770).

4. Halberg F., Cornelissen G., McCraty R., Al-Abdulgader A.A. Time structures (chronomes) of the blood circulation, populations' health, human affairs and space weather. World Heart Journal, 2011, 3(1): 1-42.

5. Halberg F., Cornelissen G., Otsuka K., Watanabe Y., Katinas G.S., Burioka N., Delyukov A., Gorgo Y., Zhao Z., Weydahl A., Sothern R.B., Siegelova J., Fiser B., Dusek J., Syutkina E.V., Perfetto F., Tarquini R., Singh R.B., Rhees B., Lofstrom D., Lofstrom P., Johnson P.W., Schwartzkopff O., the International BIOCOS Study Group. Cross-spectrally coherent $~ 10.5-$ and 21-year biological and physical cycles, magnetic storms and myocardial infarctions. Neuro Endocrinology Letters, 2000, 21(3): 233-258.

6. Khabarova O., Dimitrova S. On the nature of people's reaction to space weather and meteorological weather changes. Sun and Geosphere, 2009, 4(2): 60-71.

7. Foster K.R. Mechanisms of interaction of extremely low frequency electric fields and biological systems. Radiation Protection Dosimetry, 2003, 106(4): 301-310 (doi: 10.1093/oxfordjournals.rpd.a006364).

8. Cornélissen G., Halberg F., Breus T., Syutkina E.V., Baevsky R., Weydahl A., Watanabe Y., Otsuka K., Siegelova J., Fiser B., Bakken E.E. Non-photic solar associations of heart rate variability and myocardial infarction. Journal of Atmospheric and Solar-Terrestrial Physics, 2002, 64(5-6): 707-720 (doi: 10.1016/S1364-6826(02)00032-9).

9. Giannaropoulou E., Papailiou M., Mavromichalaki H., Gigolashvili M., Tvildiani L., Janashia K., Preka-Papadema P., Papadima T. A study on the various types of arrhythmias in relation to the polarity reversal of the solar magnetic field. Nat. Hazards, 2014, 70: 1575-1587 (doi: 10.1007/s11069-013-0890-9).

10. Caswell J.M., Carniello T.N., Murugan N.J. Annual incidence of mortality related to hypertensive disease in Canada and associations with heliophysical parameters. Int. J. Biometeorol., 2016, 60: 9-20 (doi: 10.1007/s00484-015-1000-3).

11. Panov G.A., Chizov A.Ya., Kotova I.N. Magnet storms influence on students' functional systems. Vestnik Rossiiskogo universiteta druzhby narodov. Seriya: Ekologiya i bezopasnost' zhiznedeyatel'nosti, 2008, 1: 60-67.

12. Burch J.B., Reif J.S., Yost M.G. Geomagnetic disturbances are associated with reduced nocturnal excretion of a melatonin metabolite in humans. Neuroscience Letters, 1999, 266(3): 209-212 (doi: 10.1016/s0304-3940(99)00308-0).

13. Bergiannaki J.-D., Paparrigopoulos T.J., Stefanis C.N. Seasonal pattern of melatonin excretion in humans: relationship to day length variation rate and geomagnetic field fluctuations. Experientia, 1996, 52(3): 253-258 (doi: 10.1007/BF01920718).

14. Cipolla-Neto J., Amaral F.G.D. Melatonin as a hormone: new physiological and clinical insights. Endocrine Reviews, 2018, 39(6): 990-1028 (doi: 10.1210/er.2018-00084). 
15. Pohanka M. Impact of melatonin on immunity: a review. Open Medicine, 2013, 8(4): 369-376 (doi: 10.2478/s11536-013-0177-2).

16. Rocha C.S., Rato L., Martins A.D., Alves M.G., Oliveira P.F. Melatonin and male reproductive health: relevance of darkness and antioxidant properties. Current Molecular Medicine, 2015, 15(4): 299-311 (doi: 10.2174/1566524015666150505155530).

17. Lampiao F., Du Plessis S.S. New developments of the effect of melatonin on reproduction. World J. Obstet. Gynecol., 2013, 2(2): 8-15 (doi: 10.5317/wjog.v2.i2.8).

18. Агаджанян Н.А., Макарова И.И. Магнитное поле Земли и организм человека. Экология человека, 2005, 9: 3-9.

19. Glinka M., Gawron S., Siero A., Pawłowska-Gyral K., Cieślar G., Sieroń K. Impact of static magnetic field on the antioxidant defense system of mice fibroblasts. BioMed Research International, 2018, 2018: Article ID 5053608 (doi: 10.1155/2018/5053608).

20. Zablotskii V., Polyakova T., Lunov O., Dejneka A. How a high-gradient magnetic field could affect cell life. Sci. Rep., 2016, 6: 37407 (doi: 10.1038/srep37407).

21. Marshall D.J. Environmentally induced (co)variance in sperm and offspring phenotypes as a source of epigenetic effects. Journal of Experimental Biology, 2015, 218: 107-113 (doi: 10.1242/jeb.106427).

22. Toraco E.G., García M.G., Fernández-Morera J.L., Nico-García P., Fernández A.F. The impact of external factors on the epigenome: in utero and over lifetime. BioMed Research International, 2016, 2016: Article ID 2568635 (doi: 10.1155/2016/2568635).

23. Jensen N., Allen R.M., Marshall D.J. Adaptive maternal and paternal effects: gamete plasticity in response to parental stress. Funct. Ecol., 2014, 28(3): 724-733 (doi: 10.1111/1365-2435.12195).

24. Li D.K., Yan B., Li Z., Gao E., Miao M., Gong D., Weng X., Ferber J.R., Yuan W. Exposure to magnetic fields and the risk of poor sperm quality. Reproductive Toxicology, 2010, 29(1): 8692 (doi: 10.1016/j.reprotox.2009.09.004).

25. Kumari K., Capstick M., Cassara M., Herrala M., Koivisto H., Naarala J., Tanila H., Vilukselaa M., Juutilainen J. Effects of intermediate frequency magnetic fields on male fertility indicators in mice. Environmental Research, 2017, 157: 64-70 (doi: 10.1016/j.envres.2017.05.014).

26. Борунова С.М., Иолчиев Б.С., Бадмаев О.Э., Тумилович Я.И., Иолчиев Р.Б., Рибченко А.С. Астенозооспермия у быков-производителей. Ветеринария, зоотехния $u$ биотехнология, 2017, 11: 57-64.

27. Виноградов В.Н., Стрекозов Н.И., Абилов А.И и др. Национальная технология замораживания и использования спермы племенных быков-производителей. М., 2008.

28. Wang X., Yang C., Guo F., Zhang Y., Ju Z., Jiang Q., Zhao X., Liu Y., Zhao H., Wang J., Sun Y., Wang C., Zhu H., Huang J. Integrated analysis of mRNAs and long noncoding RNAs in the semen from Holstein bulls with high and low sperm motility. Scientific Reports, 2019, 9: Article number 2092 (doi: 10.1038/s41598-018-38462-x).

29. Brody S.A. Мужское бесплодие и окислительный стресс: роль диеты, образа жизни и пищевых добавок. Андрология и генитальная хирургия, 2014, 3: 33-41 (doi: 10.17650/20709781-2014-3-33-41).

30. Gonzalez-Marin C., Gosalvez J., Roy R. Types, causes, detection and repair of DNA fragmentation in animal and human sperm cells. International Journal of Molecular Sciences, 2012, 13(11): 14026-14052 (doi: 10.3390/ijms131114026).

31. Kim G.Y. What should be done for men with sperm DNA fragmentation? Clin. Exp. Reprod. Med., 2018, 45(3): 101-109 (doi: 10.5653/cerm.2018.45.3.101).

32. Agarwal A., Said T.M. Role of sperm chromatin abnormalities and DNA damage in male infertility. Human Reproduction Update, 2003, 9(4): 331-345 (doi: 10.1093/humupd/dmg027).

33. Esteves S.C., Sanchez-Martin F., Sanchez-Martin P., Schneider D.T., Gosálvez J. Comparison of reproductive outcome in oligozoospermic men with high sperm DNA fragmentation undergoing intracytoplasmic sperm injection with ejaculated and testicular sperm. Fertility and Sterility, 2015, 104(6): 1398-1405 (doi: 10.1016/j.fertnstert.2015.08.028).

\section{1ФГБНУ ФНЦ животноводства -}

ВИЖ им. академика Л.К. Эрнста,

142132 Россия, Московская обл., г.о. Подольск, пос. Дубровицы, 60, e-mail: baylar2@mail.ru_凶, klenpm@mail.ru;

2ФГАОУ ВО Российский университет дружбы народов,

117198 Россия, г. Москва, ул. Миклухо-Маклая, 6,

e-mail: anna74@list.ru;

${ }^{3}$ ФГБОУ ВО МГМСУ им. А.И. Евдокимова

Минздрава России,

127006 Россия, г. Москва, ул. Долгоруковская, 4,

e-mail: rust1906@yandex.ru
Поступила в редакцию 13 июля 2019 года 


\title{
QUANTITATIVE AND QUALITY INDICATORS OF SPERM PRODUCTION IN HOLSTEIN BULLS DEPENDING ON GEOMAGNETIC ACTIVITY
}

\author{
B.S. Iolchiev1, P.M. Klenovitsky1, A.V. Tadzhieva², R.B. Iolchiev ${ }^{3}$ \\ ${ }^{1}$ Ernst Federal Science Center for Animal Husbandry, 60, pos. Dubrovitsy, Podolsk District, Moscow Province, 142132 \\ Russia, e-mail baylar2@mail.ru ( $\square$ corresponding author), klenpm@mail.ru; \\ ${ }_{2}^{2}$ People's Friendship University of Russia (RUDN University), 6, ul. Miklukho-Maklaya, Moscow, 117198 Russia, e-mail \\ anna74@list.ru; \\ ${ }^{3}$ Yevdokimov Moscow State University of Medicine and Dentistry, 4, ul. Dolgorukovslaya, Moscow, 127473 Russia, e-mail \\ rust1906@yandex.ru \\ ORCID: \\ Iolchiev B.S. orcid.org/0000-0001-5386-7263 \\ Klenovitsky P.M. orcid.org/0000-0003-2266-1275 \\ Tadzhieva A.V. orcid.org/0000-0002-8108-7149 \\ The authors declare no conflict of interests \\ Acknowledgements: \\ Supported financially by Russian Foundation for Basic Research, grant No. 18-016-00128 A \\ Received July 13, 2019 \\ doi: 10.15389/agrobiology.2019.6.1196eng
}

\begin{abstract}
A magnetic storm is one of the most important factors affecting the biological objects. The magnetic storms have profound effects at the molecular level, affecting certain cell structures. Spermatozoa are affected by various biotic and abiotic factors inside and outside the body. During the period of geomagnetic activity, the frequency of exacerbations of chronic diseases increases, the functions of a number of systems are disrupted. However, the reports on the influence of geomagnetic activity on the reproductive function, in particular on the quantity and quality of sperm, are objectively quite limited, and for agricultural species of animals such information was not found in the available literature. The objective of the work was to study the relationships between the geomagnetic activity and the sperm production quality and quantity parameters. The subject to the survey was the sperm collected from the Holstein-Friesian bull sires $(n=10$, Joint-Stock Company "Head Center for the Reproduction of Farm Animals", Moscow Province, 2018). Monitoring the K-index reflecting the geomagnetic conditions was carried out according to the data from the Pushkov Institute of Terrestrial Magnetism, Ionosphere and Radio Wave Propagation RAS. The statistical analysis was performed with SPSS v.15.0 for a one-way analysis of variance. The variables between the groups for $\mathrm{K} \leq 1.0$ (no geomagnetic disturbance) and $\mathrm{K} \geq 5.0$ (geomagnetic storm) were compared with the Scheffe's test. The assessment of the sperm quality was performed with the Argus-CASA software (ArgusSoft, Russia) with Nikon Eclipse Ni microscope (Nikon, Japan). Our data indicate that during the survey, the K-index was a factor affecting the biological adequacy of the bull sires. The results prove that the magnetic storm has a significant impact on the qualitative and quantitative parameters of the bull sire sperm production. We have established the statistically valid criteria for the ejaculate volumes $(F=6.49 ; p<0.05)$ and the progressively motile sperm number $(F=8.36 ; p<0.05)$ per ejaculate. The volume of the ejaculates of the bull sires tends to a $28.2 \%$ decrease $(p<0.001)$ during the magnetic storm period (K-index value $\geq 5.0$ vs. K-index $\leq 1.0$ ). The geomagnetic activity causes a $11.3 \%$ decline $(\mathrm{p}<0.001)$ in the sperm activity.
\end{abstract}

Keywords: magnetic storm, spermatozoa, sperm motility, morphology, chromatin, nDNA, DNA fragmentation index, bull sires, CASA. 